\title{
Multi-Sensory Environment and Agitated Behavior in Ageing Residents with Dementia
}

\author{
Sookyoung Lee and Agneta Morelli \\ Research Center Design and Health, Sweden \\ Atenga Health by Design, Sweden
}

\begin{abstract}
This research paper explores selected behavioral outcomes of a multi-sensory environment. An experimental study was conducted at a specialized facility for the ageing in Sweden. The objective was to explore the effects of agitated behaviors of ageing residents with dementia and to identify any short-term effects. Appointed nursing staff was instructed to record physically and verbally agitated behaviors on three occasions; pre-session, mid-session, and post-session. Over seven months, nine participants received sixty-one sessions in the multi-sensory room. ANOVA and Post hoc multiple comparisons were performed to identify the differences in mean between each session. Generally irritated/frustrated behavior and eating/drinking non foods revealed statistically significant differences, while there were no significant results in verbally agitated behavior. One short-term effect was observed in one agitated category; a reduction of generally irritated/frustrated behavior. These results suggest that the multi-sensory environment can have positive effects on some manifestations of agitated behavior. This study proposes that a multi-sensory environment may be recommended as an alternative intervention for physically agitated behavior among this category of residents. However, more research is needed to understand the specific effects and the best use of the multi-sensory environment for this population.
\end{abstract}

Keywords : Multi-sensory Environment, Agitated Behavior, Dementia, Ageing Resident

\section{INTODUCTION}

Future challenges in dementia care are complex and require developments in a wide range of areas such as organizational strategy, personnel policy, nursing care model, medical treatment as well as architecture and design. A combination of mechanisms for change is often essential to reach successful results. A growing concern is the agitated and aggressive behavior among ageing residents suffering from advanced stages of dementia.

In this study agitation is defined as inappropriate verbal, vocal, or motor activity not considered by an outside observer to be an obvious outcome of the needs or confusion of the individual (Cohen-Mansfield, 2001). The prevalence of agitated behavior among residents in care facilities varies widely. In a recent literature review, it was estimated that on average $24 \%$ of cognitively impaired elderly residents are agitated or aggressive (Brodaty \& Low, 2003). Signs of agitation among residents suffering from dementia are common, occurring at anywhere from $10 \%$ to $91 \%$ of residents in a given care facility (CohenMansfield, 2008; Kolanowski et al., 1994; Mintzer \& Brawman-Mintzer, 1996; Voyer et al., 2005). Prevalence rates, although varying widely, may therefore be very high. Agitated behavior among this population can have negative consequences. Residents with agitated behaviors

* This work was supported by the Korea Research Foundation Grant funded by the Korean Government (MOEHRD) (KRF2006-532-C00018)

** Correspondence to: S.Y. Lee, Research Center Design \& Health. Stockholm, Sweden. E-mail. sookyoung23@gmail.com are more likely to receive pharmacological treatment and physical restrain. Both interventions are well known to aggravate cognitive impairment and reduced physical strength, endurance and flexibility (Voyer \& Martin, 2003). Furthermore, the use of medication to control agitation is associated with depression and loss of functional independence (Wancata et al., 2003).

The role of the built environment in the healing process is a growing concern among architects, designers, environmental psychologies, and facility managers. Within the past fifteen years of design for dementia, researchers in Europe and the US have focused on the purposely planned multi-sensory space. Known as multisensory environments or Snoezelen rooms, these settings have been tested and used as an alternative or a compliment to medical therapy. The multi-sensory environment offers rich opportunities to experience primary sensations and can enhance verbal communication and social interaction (Pagliano, 1999).

The deliberate use of a multi-sensory room is a nonpharmacological intervention that provides an alternative approach in managing agitated behavior. Although research is limited, studies by Cohen-Mansfield \& Werner (1995) regarding environmental influences on agitation revealed that certain environmental conditions seem to affect agitation regardless of its specific manifestation. The most agitated behaviors seem to increase when residents were physically restrained, inactive, or alone. Further research on the positive effect of the multi-sensory environment on agitated behavior established a decrease in temper outbursts and wandering (Lee \& Dilani, 2008). 


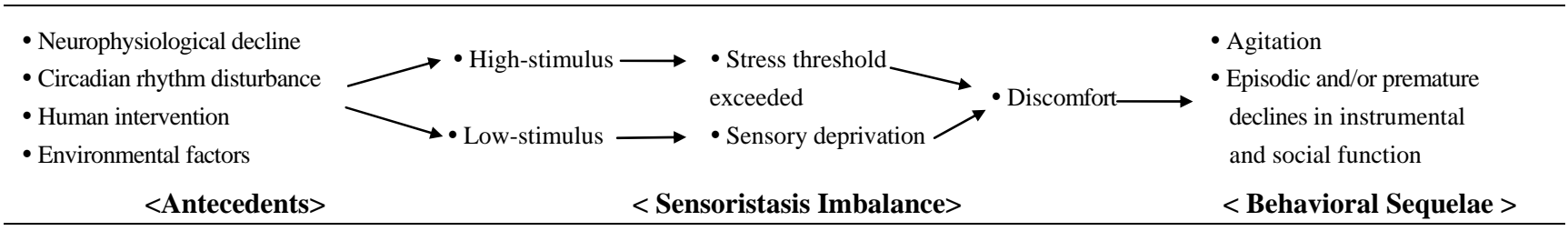

Figure 2. Model of Imbalances in Sensoristasis by Kovach (2000)

Researches by Zeisel (2009) and Lee (2010) revealed that a carefully designed environment can support behavioral functions among this population reducing the secondary symptoms of the illness; those that are not directly caused by changes to the brain, including anxiety, agitation, and aggression. These results are supported in research by Kovach \& Matovina (2001) that found agitated behavior much higher when the same level of activity was sustained for more than ninety minutes. Their studies suggest a need for balance between sensory-stimulating and sensorycalming activities. On the other hand, results from Chung and Lai (2009) imply no evidence pointing to the efficacy of Snoezelen as a multisensory environment on behaviors, mood and interaction among dementia residents. Based on the cause of the variety of multi-sensory environment's form, nature, principles, and procedures, this study suggested that more empirical and scientific studies should be conducted.

Despite advances in the field, the need for additional research motivated this experimental study focusing on the effects of a multi-sensory room and the agitated behavior of old people with dementia. The purpose of this study was i) to explore the effects of multi-sensory room and ii) to identify any short-term effects lasting up to thirty minutes.

\section{LITERATURE REVIEW}

The theoretical structures that have been applied for the elderly with dementia are focused on the concept that old people suffered with dementia experience negative consequences when they are given too much stimulation from the surrounding environment. The initial theory to conceptualize person-environment transactions were Lewin's Field Theory (1951) which indicates that behavior is a function of person and environment: $\mathrm{B}=$ $f(P, E)$ (Altman, Lawton \& Wohlwill, 1984). Lawton and Nahemow (1973) and Lawton (1982) established the person-environment transactions through the 'environmental docility hypothesis', which shows that the behavioral and emotional outcomes are negative if environmental demand exceeds a person's competence. Hall and Buckwalter (1987) offered a progressively lowered stress threshold (PLST) model, which baseline behavior and maximum functional levels can be achieved by supporting losses and by controlling stressors. According to PLST model, patient with Alzheimer's or dementia disease and related disorders becomes less able to receive and process environmental stimuli and information. This causes a progressive decline in the stress threshold, as shown in Figure 1.

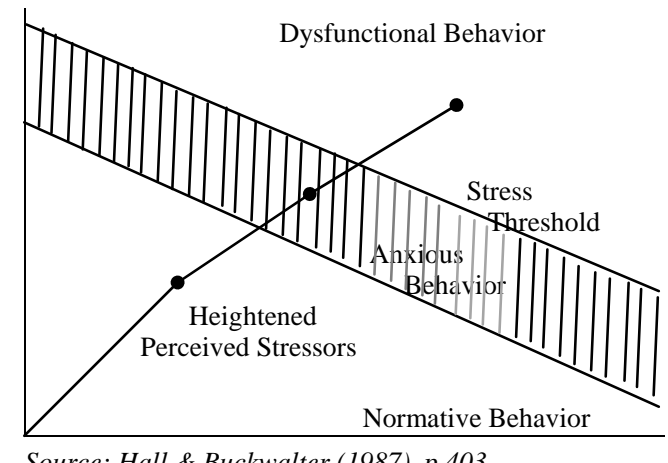

Source: Hall \& Buckwalter (1987). p.403

Figure 1. Progressively Lowered Stress Threshold in Adults with Alzheimer's and Related Disorders

The massive body of literature on the need to decrease built environmental demand or stress affected the facility for people with dementia to ameliorate the environmental stimulus; subdued colors, decreased noise, calming mood, and less activity. Meanwhile, some studies showed that too little stimulus from the surrounding environment are associated with a decline in cognition and function and an increase in behavioral symptoms (Kovach, 1997, 2000; Kovach \& Schlidt, 2001; Pragg, Kempermann \& Gage, 2000).

Kovach (2000) developed the model of imbalance in sensoristasis, which shows the need of people with dementia to experience a balance between sensorystimulating and sensory-calming activity. Sensoristasis defined as a state of equilibrium of the sensory arousal system of the person with dementia that is maintained by a dynamic pacing of sensory stimulation and sensory calming activity. When imbalances exist, agitated behaviors and declines in function can occur (Kovach, 2001). A state of imbalance is shown in Figure 2. This model is explained as follow; i) Imbalances in sensoristatsis may be caused by neurophysiological decline, disturbances in circadian rhythm, human intervention, or environmental factors. ii) Too much highstimulus activity in a given time can result in exceeding one's stress threshold. iii) Prolonged lack of stimuli can create a state of sensory deprivation. iv) States of sensory deprivation or of exceed stress threshold can result in 
intrapsychic discomfort in persons with irreversible dementia. v) Discomfort can result in agitated behavior and premature decline in instrumental and social function. vi) In situations in which activity is inadequately paced, interventions can ameliorate some of the negative consequences of imbalances.

During the last decade, a number of studies on multisensory environment have tried to prove whether multisensory environment as an intervention can ameliorate a social, emotional, and behavioral negative consequences for people with dementia. Research on the effectiveness of multi-sensory environment has been inconsistent and controversy (Baker et al., 1997; Chung \& Lai, 2009; Hope, 1998; Julia et al., 2003; Lee \& Dilani, 2008; Moffat et al., 1993; Pagliano, 1999; Shari et al., 2007). Given this circumstance, it is inevitable to perform the empirical study to explore the effect of multi-sensory environment on the maladaptive behavior.

\section{METHOD}

\section{(1) Setting}

The multi-sensory room used in this study is located on the ground floor in one of three units within a specialized facility for ageing residents with various dementia disorders in combination with challenging behavior such agitation and aggressiveness. The facility itself (referred to in this study as ' $F$ ') was built in 1950 and renovated in year 2000. It is located in a mid-size town in the central part of Sweden. The multi-sensory room was designed and ready for use in 2001 as shown in Figure 3.

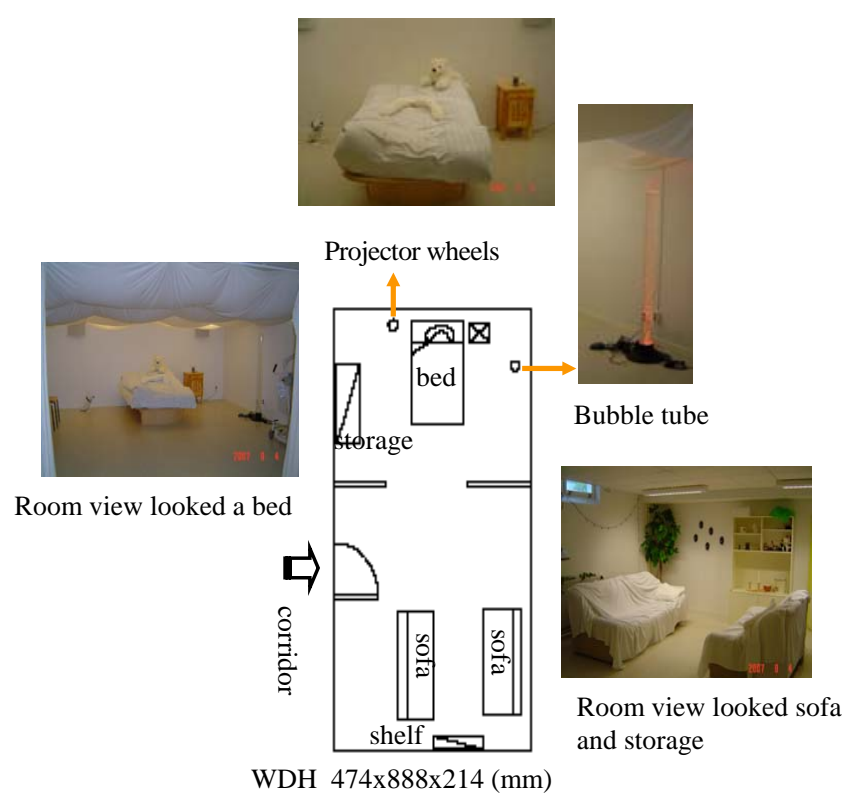

Figure 3. Layout of Multi-Sensory Room

The multi-sensory stimulation room consisted of several design features; a $200 \mathrm{~mm}$ high bubble light tube, a projector with natures scenes in view from bed position, a bed with a tube pillow and a special duvet cover filled with small lightweight pebbles, a white draped cloth ceiling, a CD player with calming sounds, an aroma diffuser, diverse tactile items on a white book shelf, two white covered couches and a white storage cupboard.

\section{(2) Participants}

Nine residents from two units participated in this study. All subjects had a diagnosis of medium to severe stage dementia. Oral consent was obtained from appointed custodians before commencing the study. Five residents were female, and four were male. Subjects ranged in age from 66 to 85 years old (mean=77.8, SD=6.3). The mean length of stay at the facility ranged from 4 months to 60 months (mean=37.8, SD=20.3). Two of the subjects participated in only two sessions each. The remaining seven underwent between three and eighteen sessions and two of those participants experienced more than ten sessions.

\section{(3) Procedure}

This study used an experimental method approach. A four week pilot phase was carried out in order to establish the suitability of assessment instruments and to conduct the procedures with four trial residents. Subsequently, a meeting was arranged to ensure staff members' full understanding of the procedure and observation instrument. Persons who had resided in this facility more than four months were selected for the study. The established list was then reviewed with staff members. Nine eligible residents were selected. One resident did not wish to enter the multi-sensory room, and was replaced by another suitable participant. The residents' appointed nurse would accompany him/her to the multi-sensory room, stay with the resident the entire session, provide support and offer tactile massage if appropriate. The nurse would then accompany the resident back to the unit. Staff was instructed to record the agitated behaviors on three occasions; pre-session (30 minutes before entering the multi-sensory room), mid-session (during the stay in the room), and post-session (30 minutes after exiting the room). Staff was asked to be as unobtrusive as possible during sessions. Over the course of seven months, nine participants were given total sixty-one sessions in the multi-sensory room. The sessions were conducted to fit with existing facility schedules. Among the sixty-one observations, thirty-eight were conducted in mid-mornings and twentythree in mid-afternoons. The duration of the multi-sensory session was a minimum of 20 minutes and a maximum of 60 minutes (mean= 37.5 minutes).

\section{(4) Observation Instrument}

The observation instrument was based on the CohenMansfield Agitation Inventory (CMAI). Inter-rater reliabilities regarding agitated behaviors for this instrument averaged 95.2\% (Cohen-Mansfield; 2007). The instrument used in the study includes 19 items that describe physical agitation (e.g., wandering, irritated/ frustrated) and verbal agitation (e.g., screaming, cursing) 
Table 1. Results of ANOVA Analysis on Agitated Behaviors

$\mathrm{N}=61$

\begin{tabular}{|c|c|c|c|c|c|}
\hline \multirow{2}{*}{\multicolumn{2}{|c|}{ Agitated Behavior }} & \multicolumn{3}{|c|}{ Means of Each Session } & \multirow{2}{*}{ F value } \\
\hline & & Pre & Mid & Post & \\
\hline \multirow{13}{*}{$\begin{array}{l}\text { Physical } \\
\text { Behavior }\end{array}$} & picking/collecting/hiding & 1.4 & 1.3 & 1.3 & N.S. \\
\hline & pushing & 1.1 & 1.1 & 1.1 & N.S. \\
\hline & temper outburst & 1.0 & 1.0 & 1.0 & N.S. \\
\hline & generally irritated/frustrated & 1.2 & 1.1 & 1.1 & $6.83^{*}$ \\
\hline & hitting/kicking & 1.0 & 1.0 & 1.0 & N.S. \\
\hline & splitting/biting & 1.0 & 1.0 & 1.0 & N.S. \\
\hline & throwing/destroying/scratching & 1.0 & 1.0 & 1.0 & N.S. \\
\hline & grab/clinging & 1.0 & 1.0 & 1.0 & N.S. \\
\hline & repetitious mannerisms & 1.0 & 1.1 & 1.1 & N.S. \\
\hline & wandering & 1.5 & 1.2 & 1.4 & N.S. \\
\hline & hurting self & 1.0 & 1.0 & 1.0 & N.S. \\
\hline & physical sexual advances & 1.0 & 1.0 & 1.0 & N.S. \\
\hline & eat/drink non food & 1.2 & 1.0 & 1.1 & $5.28^{*}$ \\
\hline \multirow{6}{*}{$\begin{array}{l}\text { Verbal } \\
\text { Behavior }\end{array}$} & crying/screaming & 1.1 & 1.1 & 1.0 & N.S. \\
\hline & complaining & 1.1 & 1.0 & 1.0 & N.S. \\
\hline & verbal threats & 1.0 & 1.0 & 1.0 & N.S. \\
\hline & verbal sexual advances & 1.0 & 1.0 & 1.0 & N.S. \\
\hline & making strange noises & 1.1 & 1.1 & 1.1 & N.S. \\
\hline & cursing/verbal aggression & 1.1 & 1.1 & 1.1 & N.S. \\
\hline
\end{tabular}

$* P<.01$

N.S.: not statistically significant

behaviors. A Likert scale of measurement was applied to items on the rating scales ranging from $5=$ present to an extreme degree to $1=$ the behavior is not present to obtain quantitative data.

\section{(5) Analytic Approach}

To examine whether the mean of agitated behaviors during sessions was different, ANOVA tests were conducted using Excel (2007 version) to indicate whether the change in subject's agitated behavior differed between the sessions according to the F-value. As an auxiliary analysis, Post hoc multiple comparisons analysis using SPSS 17.0 version was performed to identify the differences in mean between each session: between presessions and mid-sessions, mid-sessions and post-sessions, and pre-sessions and post-sessions.

\section{RESULTS}

\section{(1) General results of ANOVA analysis}

The means for each behavior category at each session, F-value, and significance level are presented in Table 1. ANOVA test revealed statistically significant differences in the generally irritated/frustrated behavior $\left(\mathrm{F}_{(2,182)}=\right.$ 6.83, $p<.01)$ and eating/drinking non-food behavior ( $\mathrm{F}$ $(2,182)=5.28, p<.01)$ in physical agitated behavior, while there were not significant discrepancies in verbally agitated behavior. In case of wandering behavior, participants showed less wandering during the stay in the multi-sensory room although mean values showed no statistical differences. In order to isolate at which stage of the session the differences occurred, post hoc multiple comparisons were conducted on the generally irritated/ frustrated and eating/drinking non-food agitated behaviors.

$<$ Irritated/frustrated behavior $>$

Figure 4 demonstrates the means of the generally irritated/frustrated behaviors in pre-, mid-, and postsession as 1.21, 1.06, and 1.06 respectively. As an auxiliary analysis, post hoc multiple comparisons were made to compare the means of the behavior between the sessions. The result is shown in Table 2. In the multiple comparisons, there were significant differences between pre- and mid-sessions, and between pre- and post-sessions with $p$ values .10, while there was no significant difference between mid- and post-sessions. The category generally irritated/frustrated behavior reduced during the stay in the multi-sensory room and continued to reduce at least 30 minutes after exiting the room.

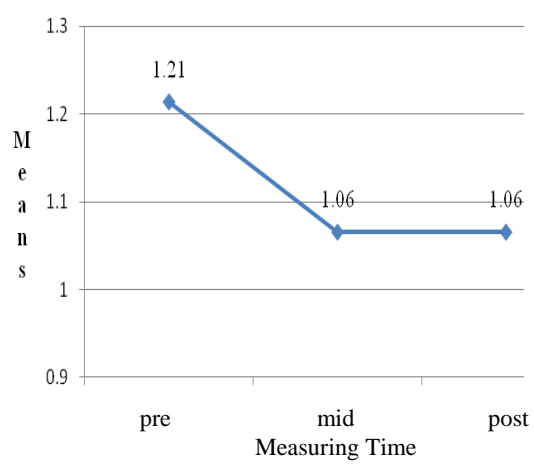

Figure 4. Means of Generally Irritated/Frustrated Behavior 
Table 2. Multiple Comparisons: Irritated behavior

\begin{tabular}{|c|c|c|c|c|c|c|}
\hline \multirow{2}{*}{$\begin{array}{l}\text { (I) } \\
\text { measur } \\
\text { etime }\end{array}$} & \multirow{2}{*}{$\begin{array}{l}(\mathrm{J}) \\
\text { measure } \\
\text { time }\end{array}$} & \multirow{2}{*}{$\begin{array}{l}\text { Mean } \\
\text { Difference } \\
(\mathrm{I}-\mathrm{J})\end{array}$} & \multirow[b]{2}{*}{$\begin{array}{l}\text { Std. } \\
\text { Error }\end{array}$} & \multirow[b]{2}{*}{ Sig. } & \multicolumn{2}{|c|}{ 90\% Confidence Interval } \\
\hline & & & & & $\begin{array}{l}\text { Lower } \\
\text { Bound }\end{array}$ & $\begin{array}{l}\text { Upper } \\
\text { Bound }\end{array}$ \\
\hline \multirow{2}{*}{ Pre } & Mid & $.148^{*}$ & .066 & .080 & .01 & .29 \\
\hline & Post & .145 & .067 & .091 & .00 & .29 \\
\hline \multirow{2}{*}{ Mid } & Pre & $-.148^{*}$ & .066 & .080 & -.29 & .00 \\
\hline & Post & -.002 & .067 & 1.000 & -.15 & .14 \\
\hline \multirow{2}{*}{ Post } & Pre & $-.145^{*}$ & .067 & .091 & -.29 & .00 \\
\hline & Mid & .002 & .067 & 1.000 & -.14 & .15 \\
\hline
\end{tabular}

$<$ Eating/drinking non-food behavior $>$

The means of the eating/drinking non-food behavior in pre-, mid-, and post-sessions were 1.23, 1.00, and 1.10 respectively as shown in Figure 5. In order to identify where differences were observed during sessions, a multiple comparisons for the eating/drinking non-food behavior were conducted as shown in Table 3. The analysis showed a significant difference between pre- and midsessions with $p$ values .020 , while in the post-sessions, there were no significant differences compared to pre- and mid-sessions. Subjects had considerably less eating/drinking non-food behaviors while in the multisensory room. The decreased behavior did not continue after the subjects left the room.

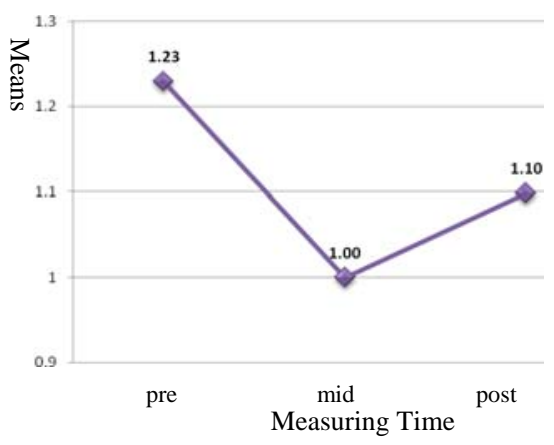

Figure 5. Means of Eating/Drinking Non-Food Behavior

Table 3. Multiple Comparisons: Eating/drinking non-food

\begin{tabular}{lllcccc}
\hline & & & & & \multicolumn{2}{c}{$\begin{array}{c}\text { 95 Confidence } \\
\text { Interval }\end{array}$} \\
\cline { 6 - 8 } $\begin{array}{l}\text { I) } \\
\text { measur } \\
\text { etime }\end{array}$ & $\begin{array}{l}\text { measur } \\
\text { etime }\end{array}$ & $\begin{array}{c}\text { Mifference } \\
(\mathrm{I}-\mathrm{J})\end{array}$ & $\begin{array}{c}\text { Std. } \\
\text { Error }\end{array}$ & Sig. & $\begin{array}{c}\text { Lower } \\
\text { Bound }\end{array}$ & $\begin{array}{c}\text { Upper } \\
\text { Bound }\end{array}$ \\
\hline \multirow{2}{*}{ Pre } & Mid & $.230^{*}$ & .084 & .020 & .03 & .43 \\
& Post & .128 & .085 & .397 & -.08 & .33 \\
\hline \multirow{2}{*}{ Mid } & Pre & $-.230^{*}$ & .084 & .020 & -.43 & -.03 \\
& Post & -.102 & .085 & .692 & -.31 & .10 \\
\hline \multirow{2}{*}{ Post } & Pre & -.128 & .085 & .397 & -.33 & .08 \\
& Mid & .102 & .085 & .692 & -.10 & .31 \\
\hline
\end{tabular}

$* P<.05$
(2) Results of ANOVA analysis of observation time

To test the statistical significance of differences between observations conducted mid-mornings and midafternoons, ANOVA tests were conducted. Table 4 shows that no significant result were found with the exception of wandering $\left(\mathrm{F}_{(2,113)}=5.66, p<.05\right)$ and eating/drinking non food $\left(\mathrm{F}_{(2,113)}=5.74, p<.05\right)$. Results confirm that the multi-sensory room had an effect on some of the agitated behaviors during the mid-morning sessions but not in the mid-afternoon sessions. In order to identify which of the session stages that differed, post hoc multi-comparison test were conducted for the wandering behavior and eating /drinking non food behavior.

Table 4. Results of ANOVA Analysis according to the Observation Time

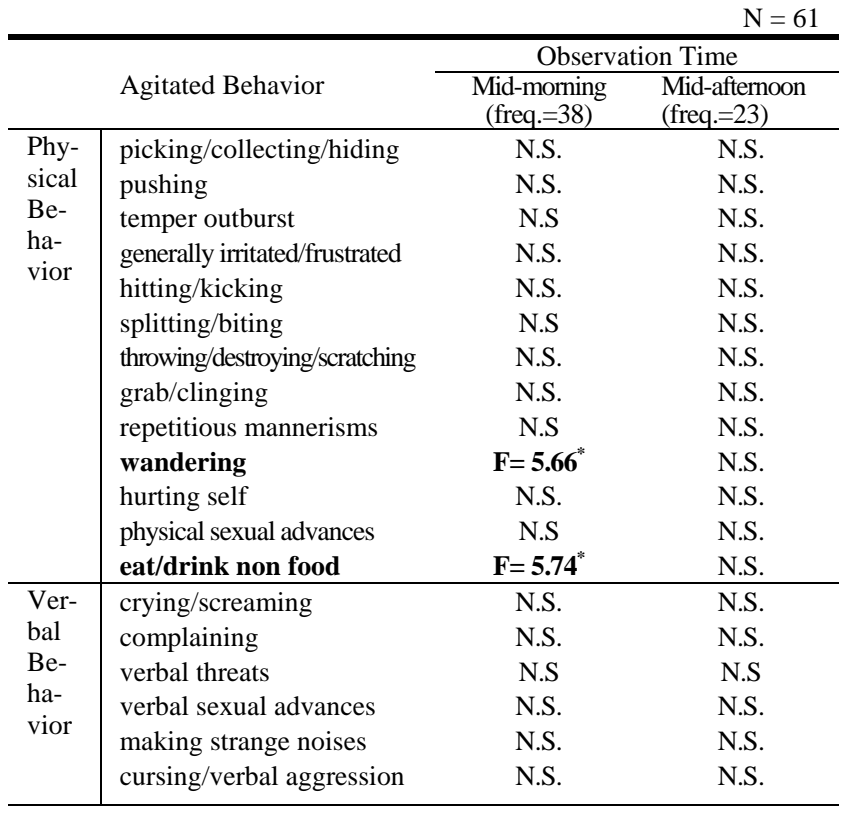

Degree of freedom $=2,113$

$* P<.05$

N.S.: no significant

$<$ Wandering behavior $>$

Figure 6 shows the means for wandering behavior. In the mid-morning observations, the mean of pre-session measurements was 1.47, mid-session 1.11, and postsession 1.50. While not statistically significant, the means from the mid-afternoon observations were 1.52 (pre), 1.35 (mid), and 1.30 (post). Table 5 shows the statistically significant differences between mid-session observations and both pre- and post-session observations with a $p$ value .022 and .014 respectively. It would indicate that participants reduced the wandering behavior while staying in the multi-sensory room during mid-mornings, but upon leaving the room, the wandering behavior reverted back to the same levels as before. 


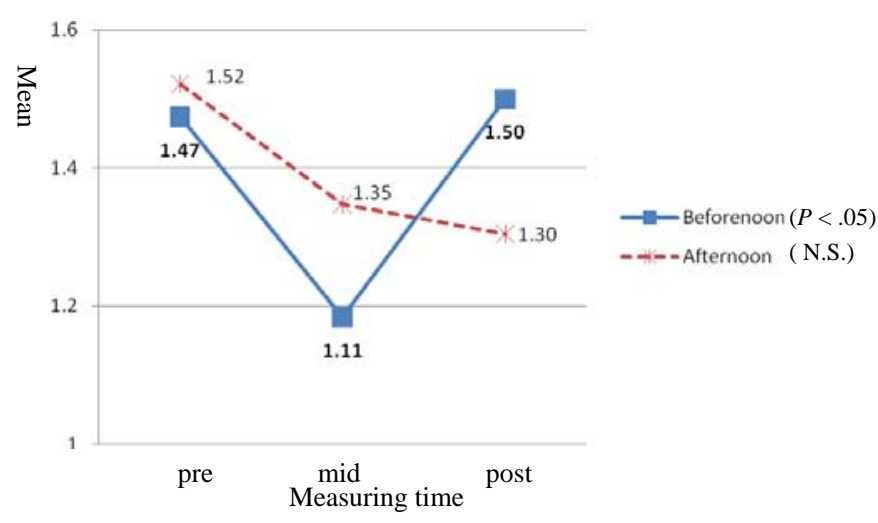

Figure 6. Means of Wandering Behavior of the Mid-Morning Observations

Table 5. Multiple Comparisons of Wondering of the Mid-Morning Observations

\begin{tabular}{|c|c|c|c|c|c|c|}
\hline \multirow[b]{2}{*}{$\begin{array}{l}\text { (I) } \\
\text { Measur } \\
\text { etime }\end{array}$} & \multirow[b]{2}{*}{$\begin{array}{l}\text { (J) } \\
\text { Measur } \\
\text { etime }\end{array}$} & \multirow[b]{2}{*}{$\begin{array}{l}\text { Mean } \\
\text { Difference } \\
(\mathrm{I}-\mathrm{J})\end{array}$} & \multirow[b]{2}{*}{$\begin{array}{l}\text { Std. } \\
\text { Error }\end{array}$} & \multirow[b]{2}{*}{ Sig. } & \multicolumn{2}{|c|}{$\begin{array}{l}\text { 95\% Confidence } \\
\text { Interval }\end{array}$} \\
\hline & & & & & $\begin{array}{l}\text { Lower } \\
\text { Bound }\end{array}$ & $\begin{array}{l}\text { Upper } \\
\text { Bound }\end{array}$ \\
\hline \multirow{2}{*}{ Pre } & Mid & $.366^{*}$ & .133 & .022 & .04 & .69 \\
\hline & Post & -.026 & .134 & 1.000 & -.35 & .30 \\
\hline \multirow{2}{*}{ Mid } & Pre & $-.366^{*}$ & .133 & .022 & -.69 & -.04 \\
\hline & Post & -.392 & .135 & .014 & -.72 & -.06 \\
\hline \multirow{2}{*}{ Post } & Pre & .026 & .134 & 1.000 & -.30 & .35 \\
\hline & Mid & $.392^{*}$ & .135 & .014 & .06 & .72 \\
\hline
\end{tabular}

$<$ Eating/drinking non food $>$

The means for eating/drinking non food behavior during the mid-morning observations are presented in Figure 7. They were 1.29 at pre-session, 1.00 at midsession, and 1.08 at post-session. While not statistically significant, the means from the mid-afternoon observations were 1.13 (pre), 1.00 (mid), and 1.13 (post). To examine which sessions differed significantly, a multi-comparison analysis was conducted for the behavior. Table 6 shows that a presession mean with a significant difference to midsession with a $p$ value .030 . It implies that participants showed less eating /drinking non food behavior while staying in the multi-sensory room at mid-morning observations, but that this agitated behavior was not reduced after leaving the room.

Merging Table 5, 6 reveals that participants reduced the agitated behavior of the wandering and eating/drinking non food while staying in the multisensory room during the mid-morning observations. These agitated behavior categories were present on approximately the same level as before entering the multi-sensory room.

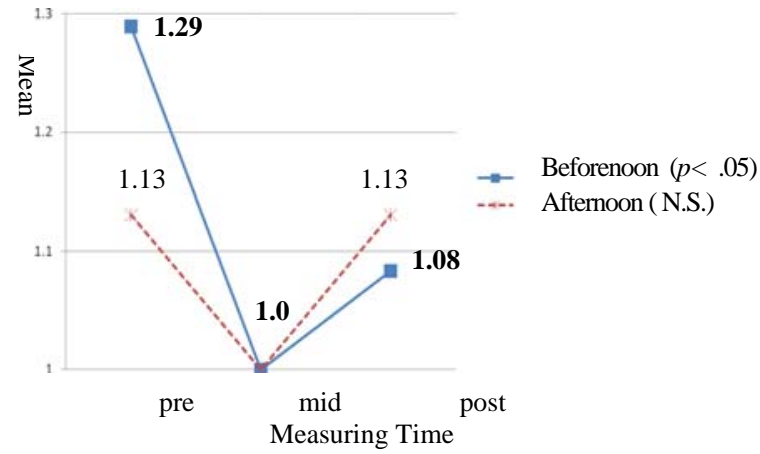

Figure 7. Means of Eating/Drinking Non Food Behavior of Mid-Morning Observations

Table 6. Multiple Comparisons of Eating/Drinking Non-food of MidMorning Observation

\begin{tabular}{|c|c|c|c|c|c|c|}
\hline \multirow{2}{*}{$\begin{array}{l}\text { (I) } \\
\text { Meas } \\
\text { ureti } \\
\text { me }\end{array}$} & \multirow{2}{*}{$\begin{array}{l}\text { (J) } \\
\text { Measur } \\
\text { etime }\end{array}$} & \multirow{2}{*}{$\begin{array}{c}\text { Mean } \\
\text { Difference } \\
(\mathrm{I}-\mathrm{J})\end{array}$} & \multirow[b]{2}{*}{ Std. Error } & \multirow[b]{2}{*}{ Sig. } & \multicolumn{2}{|c|}{$\begin{array}{l}\text { 90\% Confidence } \\
\text { Interval }\end{array}$} \\
\hline & & & & & $\begin{array}{l}\text { Lower } \\
\text { Bound }\end{array}$ & $\begin{array}{l}\text { Upper } \\
\text { Bound }\end{array}$ \\
\hline \multirow{2}{*}{ Pre } & Mid & $.289^{*}$ & .110 & .030 & .05 & .53 \\
\hline & Post & .206 & .111 & .198 & -.03 & .45 \\
\hline \multirow{2}{*}{ Mid } & Pre & $-.289^{*}$ & .110 & .030 & -.53 & -.05 \\
\hline & Post & -.083 & .112 & 1.000 & -.32 & .16 \\
\hline \multirow{2}{*}{ Post } & Pre & -.206 & .111 & .198 & -.45 & .03 \\
\hline & Mid & .083 & .112 & 1.000 & -.16 & .32 \\
\hline
\end{tabular}

\section{DISCUSSION}

The results of this experimental study suggest that the multi-sensory environment can have positive effects on some manifestations of agitated behavior. Participants within the multi-sensory room demonstrated significantly lower levels of generally irritated/frustrated behavior and eating/drinking non food behavior. These findings contrast with those of Chung and Lai (2009), which reported no evident effect of multi-sensory environment on the agitated behavior of dementia residents. The inconsistent result may derive from the different cultural, psychological, or personnel background of the participants as well as the variety of multi-sensory environment's forms, nature, and procedures. Meanwhile the results are consistent with the studies of Baker et al. (1997), Cornell (2004), and Moffat et al. (1993) showing a positive mood/ behavior change such as facilitating verbal expression and memory recall, happiness, and calmness. Results revealed that two categories of physically agitated behavior were reduced while staying in the multi-sensory environment. Residents with eating/drinking inedible food behavior and generally irritated behavior seemed to shift their focus in multi-sensory environment. Based on these findings, the setting may alleviate anxiety and promote interest among 
elderly residents with dementia by controlling sensory input. However, results on verbal agitation revealed no significance. In Cohen-Mansfield \& Werner's study (1995), verbally disruptive behaviors may be associated with discomfort and/or lacking in intimacy. Their explanation may offer an explanation to the constant and low levels of verbally agitated behaviors. Residents in this study may experience their surroundings generally comforting and the multi-sensory room experience may have felt generally calming as residents were accompanied by a nurse.

One continued short-term effect was observed in one agitated category; a reduction of generally irritated/ frustrated behavior. Regarding after effects, Baker and his associates (1997) found that the multi-sensory environment helped improve relaxation, facilitated verbal expression, as well as a happy/content condition. However, there is a need for stronger evidences to generalize these findings. Results on the short- and long term effects of multi-sensory environments have been both limited and inconsistent.

During mid-morning observations, the participants showed significantly lower levels of wandering and eating/drinking non food in the experimental space. The causes of such agitated behaviors include pharmacological side effects, stress and fear (www.alz.org). In view of the various origins of agitation, it appears that the experimental setting can settle down certain types of the restless behavior. This result is supported in the Julia et al. (2005) study on the multi-sensory room where subjects showed significant changes in well-being and adaptive behavior during morning care.

Limitations of this study include the lack of a control cohort to increase the experimental reliability and of objective assessment variables such as a heart rate, blood pressure, or stress measurement. Participant responses to the sessions varied for each person and sometimes for the same person from time to time. This consideration suggests that a detailed analysis of individual responses was lacking in this study. To improve reliability and generalization in the future requires both larger data collection and the addition of an objective assessment methodology.

\section{CONCLUSION}

This experimental study was planned to focus on the effects of a multi-sensory room and the agitated behavior of old people with dementia. The study has indicated selected positive effects of the multi-sensory environment on certain physically agitated behavior among ageing residents suffering from dementia. Results indicate benefits in three areas as follows;

First, this study supports the multi-sensory environment as an alternative intervention approach. It implies a possible reduction in generally irritated/frustrated behavior, wandering, and eating inedible food. It is significant to note that the reduction of eating inedible food was observed through this experimental study while it has not been found in other studies. Given the frequency of agitation and wandering behaviors reported from dementia facilities, multi-sensory environments seem to be a worthwhile approach.

Second, it may be natural for the elderly suffering with dementia to be shown a negative consequence under the unfamiliar surroundings. In spite of that, it should not be forgotten that the multi-sensory setting has no harmful side effects or known negative consequences. In this perspective, an arrangement of the multi-sensory healing environmental along with pharmaceutical treatment seem to be most effective health care approach in advanced dementia. The unique properties of the multi-sensory environment may offer valuable treatment intervention for this population.

Finally, the multi-sensory environment, however, had limited short-term effects on the agitated behavior. After leaving the multi-sensory environment, participants' behavior reverted back to their previous manner. This finding does not reduce the value of a multi-sensory environment for the elderly with severe dementia; as frequent and satisfying moments are vital to experienced quality of life.

The multi-sensory environment incorporates both stimulation and relaxation. Based on the study, the multisensory room as an alternative healing environment deserves to be considered in the planning of the elderly care facilities in Korea. The setting may provide the Korean society an opportunity to improve elderly care systems and therapeutic approaches including physical and occupational therapy.

\section{REFERENCES}

Altman I., Lawton M.P. \& Wohlwill J. F. (1984). Elderly People and the Environment. Plenum Press: N.Y. \& London

Baker R. et al. (1997). Snoezelen: its long-term and shortterm effects on older people with dementia. British Journal of Occupational Therapy. Vol.60 (5). 213-218

Brodaty H. \& Low L.,F.(2003). Aggression in the elderly. Journal of Clinic Psychiatry, 64 (Suppl 4):36-43.

Chung J. \& Lai C. (2009). Snoezelen for Dementia. John Wiley \& Sons, Ltd.

CMAI (http://www.medafile.com/zyweb/CMAI.htm)

Cohen-Mansfield J. (2008). Agitated behavior in persons with dementia: The relationship between type of behavior, its frequency, and its disruptiveness. Journal of Psychiatric Research. Vol.43 (1). 64-69

(2007). Temporal patterns of agitation in dementia. American Association for Geriatric Psychiatry. Vol. 15 (5). 395-405

Cohen-Mansfield J. (2001). Managing agitation in elderly patients with dementia. Geriatric Time. Vol.II (3). http://www.cmellc.com/geriatrictimes/g010533.html 
Cohen-Mansfield J. \& Werner P. (1995). Environmental influences on agitation: An integrative summary of an observational study. The American Journal of Alzheimer's Care and Related Disorders and Research. Vol. 10 (32). 32-39

Cornell A. (2004). Evaluating the effectiveness of Snoezelen on women who have a dementing illness. International Journal of Psychiatric Nursing Research. Vol.9 (2). 1045-62

Hall G.R. (1994). Caring for people with Alzheimer's disease using the conceptual model of progressively lowered stress threshold in the clinical setting. Nursing Clinics of North America. Vol.29(1). 129-141

Hall G.R. \& Buckwalter K.C. (1987). Progressively lowered stress threshold: A conceptual model for care of adults with Alzheimer's disease. Archives of Psychiatric Nursing. Vol.1(6). 399-406

Hope K.W. (1998). The effects of multi-sensory environments on older people with dementia. Journal of Psychiatric and Mental Health Nursing. Vol.5. 377-385

Julia C.M. et al. (2005). Behavioral and mood effects of Snoezelen integrated into 24-hour dementia care. American Geriatrics Society. Vol.53 (1). 24-33

Kolanowski A., Hurwitz S., Taylor L.A., Evans L. \& Strumpf N. (1994). Contestual factors associated with disturbing behaviors in institutionalized elders. Nursing Research. Vol. 43 (2). 73-79

Kovach, C. R. (2000). Sensoristasis and imbalance in persons with dementia. Journal of Nursing Scholarship. Fourth Quarter. 379-384

(1997). Late-stage dementia care: A basic guide. Washington DC: Taylor \& Francis.

Kovach, C. R. \& Schlidt A.M. (2001) The agitationactivity interface of people with dementia in long-term care. American Journal of Alzheimers's Disease and other Dementias. Vol. 16 (4), July/August. 240-246

Lee S. Y. (2010). Therapeutic environmental design effect on behavioral health for the elderly with dementia. Research Report submitted to Korea Research Foundation (Unpublished).

Lee S. Y. \& Dilani A. (2008). Effects of Snoezelen room on agitated behavior of people with dementia. Journal of the Korean Housing Association. Vol.19 (4). 79-87

Mintzer J.E. \& Brawman-Mintzer O. (1996). Agitation as a possible expression of generalized anxiety disorder in demented elderly patients: toward a treatment approach. Journal of Clinic Psychiatry. Vol. 57. Suppl.7. 55-63

Moffat N. et al. (1993). Snoezelen: An experience for people with dementia. Chesterfield, Derbyshire; Rompa

Pagliano P. (1999). Multisensory Environments. London: David Fulton.

Praag H., Kempermann G. \& gage F. H. (2000). Neural consequences of environmental enrichment. Nature Reviews Neuroscience. Vol.1(3). 191-198

Richards K.C. \& Beck C.K. (2004). Progressively lowered Stress threshold model: Understanding behavioral symptoms of dementia. The American Geriatrics Society. Vol. 52. 1774-1775
Sarah B. et al. (2005). Variability in response of older people with dementia to both Snoezelen and reminiscence. British journal of Occupational Therapy. Vol.68 (8). 367-374

Shari A.M. (2007). Effects of a Snoezelen room on the behavior of three autistic clients. Research in Developmental Disabilites. Vol.28. 304-316

Voyer P. et al. (2005). Prevalence of physical and verbal aggressive behaviors and associated factors among old adults in long-term care facilities. BMC Geriatrics. Vol.5(13).

Voyer P. \& Martin L.S. (2003). Improving geriatric mental health nursing care: making a case for going beyond psychotropic medications. International Journal of Mental Health and Nurse, Vol. 12. 11-21.

Wancata, J., Benda, N., Meise, U., Windhaber, J. (2003). Non-cognitive symptoms of dementia in nursing homes: frequency, course and consequences. Social Psychiatry Epidemiol . Vol.38. 637-643.

Zeisel J. (2009). I'm Still Here. Avery: Penguin Group Inc. p. 20

(Date of Submission : 2010.2.2) 